\title{
APPENDICEAL RECURRENT COLIC DUE TO ENTEROBIUS VERMICULARIS INFECTION IN A 14-YEAR-OLD FEMALE PATIENT
}

\section{Toni I. Stoyanov, Emilio Corral-Fernadez, Antonio Melero-Abellan, Pablo Sarduy-Fernandez, Paloma Casado-Santamaria, Elias Garcia-Grimaldo, Julio Valer Corellano", Kaloyan T. Ivanov', Nikolay H. Kolev ${ }^{3}$, Pencho T. Tonchev ${ }^{3}$}

\section{Department of General Surgery, General Hospital of Villarobledo, Spain \\ ${ }^{1}$ Department of Pathology, University Hospital of Albacete, Spain \\ ${ }^{2}$ Department of Surgery, MHAT-Medica, Ruse, Bulgaria \\ ${ }^{3}$ Medical University - Pleven, Bulgaria}

\author{
Corresponding Author: \\ Toni I. Stoyanov \\ Department of General Surgery, \\ General Hospital of Villarobledo, \\ Avenue Miguel de Cervantes, \\ c/v aCtra El Provencio km 0.3, \\ Villarobledo (Albacete), 02600, \\ Spain \\ e-mail:dr_stoyanov@yahoo.com
}

Received: December 12, 2016

Revision received: December 16, 2016

Accepted: December 20, 2016

\section{Summary}

Acute appendicitis due to Enterobius vermicularis, usually known as pinworm, is very rare and affects mostly children. According to different authors, it is controversial whether pinworms cause inflammation of the appendix or appendiceal colic only. We present a case of a 14-year-old female with three subsequent hospitalizations in 1 month due to abdominal pain in the right lower abdomen, with rebound tenderness, normal CT scan and laboratory findings. During the last hospitalization, laparoscopic appendectomy was performed. Intraoperatively multiple pinworms were found in the appendix. These were trapped by a stercolith in the appendicular base in a noninflamed and histologically normal appendix. Two oral doses of mebendazole were administered postoperatively. Uneventful postoperative period and postoperative follow-up showed lack of symptoms six months after the operation. Despite the widespread idea that acute appendicitis due to Enterobius vermicularis is very rare, it should always be considered in young female patients with repeated abdominal pain in the right lower abdomen with normal laboratory and radiologic findings.

Key words: Enterobius vermicularis, acute appendicitis, laparoscopic appendectomy

\section{Introduction}

Enterobius vermicularis, also called pinworm, is a cause for a widespread parasitic helminthes infection, assessed to affect up to 209 million people worldwide [1]. Enterobius ova were found in human coprolites from 7800 BC [2]. Fabricius Hildanus was the first to report pinworms in appendix in 1634 [3]. Many authors considered this infection not to be a serious disease because of its low pathogenicity. However, E. vermicularis has been reported to be involved in various surgical disorders such as colitis, perianal abscess or granulomas, significant morbidity in females with ectopic infections, chronic pelvic pain, pelvic inflammatory disease. It is also associated with acute appendicitis [4]. The relationship of pinworm infection with acute appendicitis fluctuates from 0.2 to $41.8 \%$ [5]. The role of E. vermicularis in acute appendicitis has been discussed since it was found in the appendiceal lumen in 1898. However, revision of the literature 
confirms that $E$. vermicularis infestation of the appendix is able to manifest clinical signs of acute appendicitis known in the literature as appendiceal colic.

\section{Case Presentation}

We present a case of a 14-year-old female with three subsequent hospitalizations in 14 days for abdominal pain in the right lower abdomen. Physical examination showed good general

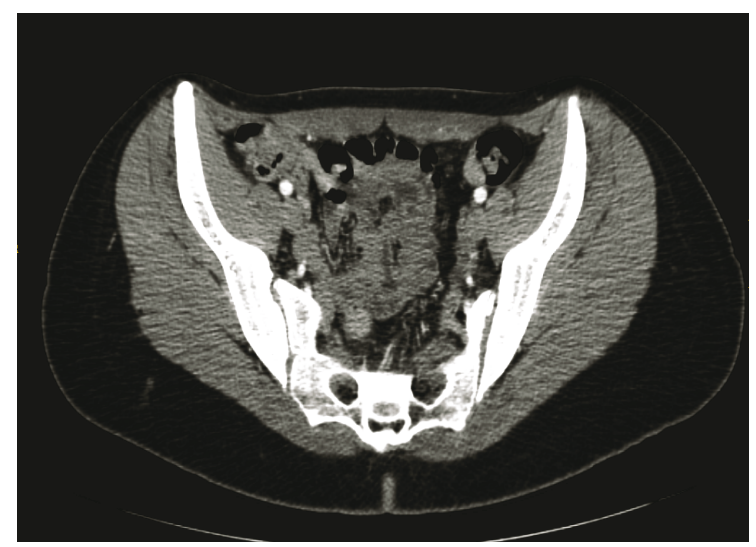

Figure 1. CT scan

On the third hospitalization, a decision for surgery was made because of the ongoing signs of abdominal pain in the right iliac fossa, tenderness, rigidity, and leukocytosis. The standard 3-port technique for laparoscopic appendectomy was applied. Intraoperatively, the appendix was found normal. The mesoappendix was dissected using LigaSure, 2 endo-loops of PDS 0 were applied to the base of the appendix -

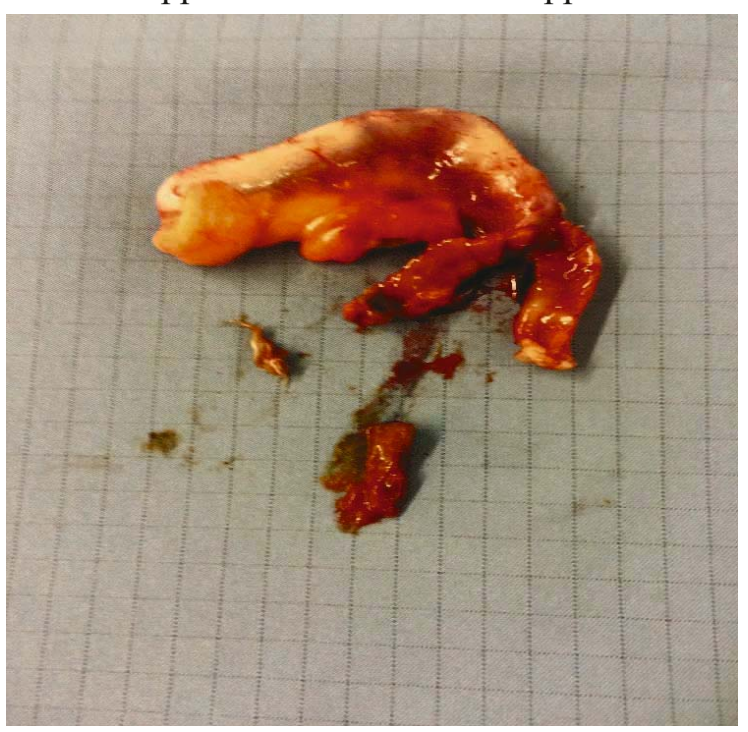

Figure 2. Operative specimen health and fever up to $38^{\circ} \mathrm{C}$ on the third hospitalization. Right lower quadrant tenderness and rigidity were found on abdominal palpation during each hospitalization. The laboratory test were normal, only in the third hospitalization the white blood cell count (WBC) was $12 \times 10^{9}$ cells/L, with normal levels of C-reactive protein $(<1 \mathrm{mg} / \mathrm{L})$. Ultrasonography during the first hospitalization and CT scan during the second one revealed a normal appendix with no signs of appendicitis (Figure 1).

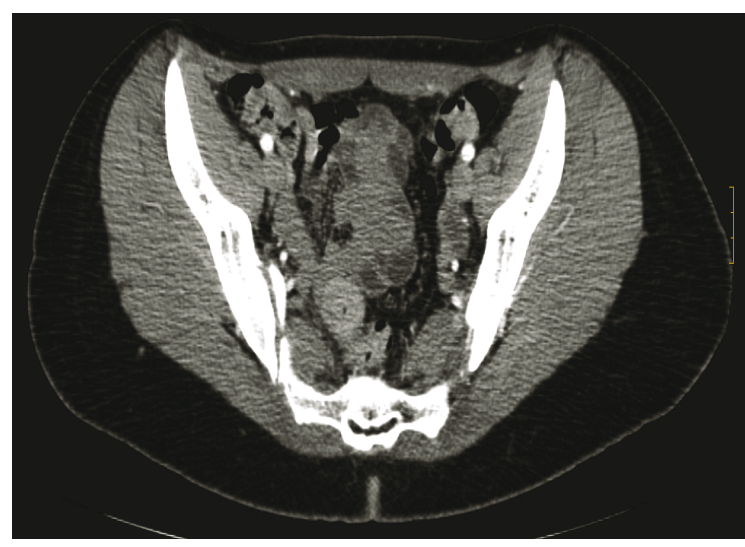

one proximal and one distal, and the appendix was divided between them. The specimen was then removed using a bag (EndoCatch) through the $10 \mathrm{~mm}$ port, under direct vision.

After dividing the appendicular base, multiple pinworms were seen in the appendix, trapped inside by a stercolith located in the appendicular base (Figure 2).

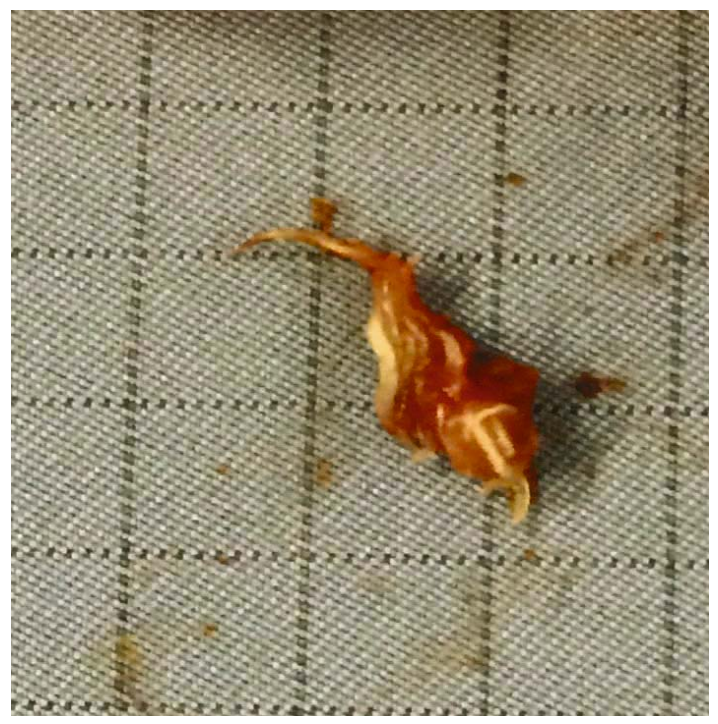


The appendix was histologically normal and non-inflamed. The lumen contained parasites with features compatible with $E$. vermicularis. The diagnosis was parasitic infestation in surgically removed normal appendices (Figure $3)$.

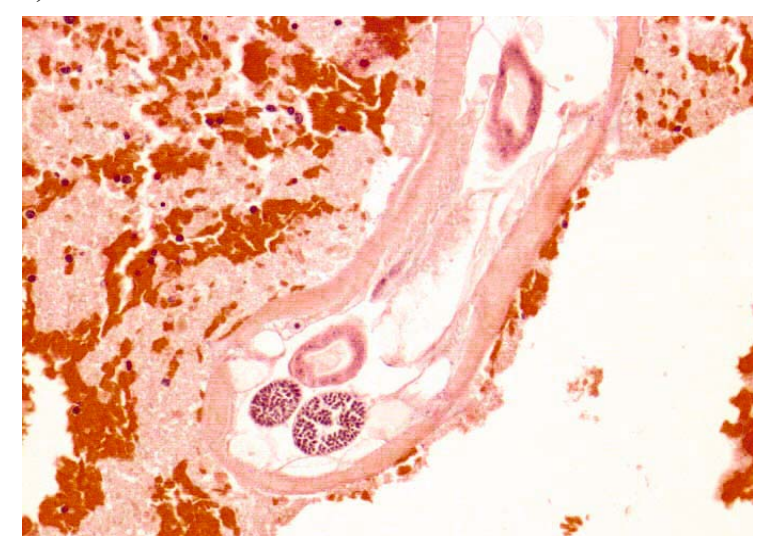

Figure 3. Histology specimen. Oblique cut of Enterobius vermicularis located in ileocecal appendiceal light. (hematoxylin-eosin 20x)

The postoperative period was smooth without any complication, and the patient was discharged from hospital on the third postoperative day.

Postoperatively, a Sellotape test (scotch tape test) was performed according to Graham's technique, and culture of parasites in feces with eggs of E. vermicularis was observed. During the postoperative period, the patient received antiparasitic treatment with mebendazole, a single peroral dose of $100 \mathrm{mg}$, and the absence of eggs of pinworm was confirmed with another Sellotape test 7 days after the first one. The patient received a second treatment with mebendazole after 15 days, and the same treatment was prescribed for the all family members.

\section{Discussion}

E. vermicularis is a parasite hosted by humans and approximately 1000 million people worldwide are infected [4]. It is acquired by ingesting larval eggs. In the intestine the larvae, released by the eggs, migrate to the colon and attach to the mucosa. They remain in the caecum or in the caecal appendix silently or produce obstruction of the appendicular lumen, triggering a clinicopathological picture of acute appendicitis indistinguishable from that due to other causes.

It is more frequently found in females, with a peak in 12-year-old girls [6]. Therefore, in children and juvenile patients with abdominal pain in the right iliac fossa without analyticalradiological alterations in the ileocaecal appendix, this infectious pathology must be considered, proceeding to the subsequent medical treatment and avoiding unnecessary appendectomies.

Even though inflammation in the ileocolic part of the intestinal tract caused by $E$. vermicularis was reported in 1919, it still remains controversial whether the parasite causes acute appendicitis or only a so-called appendiceal colic [7].

One challenge to surgeons is how to avoid spillage of the pinworms during laparoscopy. Appendectomy should be performed with caution if the appendix has been found uninflamed and there is a possibility of pinworm infection and risk of abdominal contamination. Ariyarathenam AV. et al. recommend placing a bag inside the abdomen next to the specimen, prior to cutting the appendix to ensure an easy transfer of the specimen into the bag. The appendix must not be detached in one swift motion because this will produce retraction on the appendicecal base and raise the probability of abdominal contamination [4]. Spillage of the parasites should also be avoided by putting 2 endoloops on both sides of the appendix base or cutting the appendix with GIA [8]. In our hospital we usually used two PDS endoloops on both sides of the appendix.

The correlation between parasitic infection of the appendix and acute appendicitis was investigated. Retrospective studies showed that E. vermicularis is the commonest worm found in the appendix and its existence can lead to pathologic disorders ranging from lymphoid hyperplasia to acute inflammation with lifethreatening complications like gangrenous appendicitis and local or diffuse peritonitis [9, 10]. According to a retrospective study by Gialamas et al., of the 1085 appendectomies performed in Greece, 8 patients were found with pinworm infestation. Seven of them had $E$. vermicularis infection without appendicitis and only one patient showed evidence of concurrent appendiceal inflammation.

In our case the histology showed normal appendix with parasites inside the lumen.

After surgery, the drug of choice for $E$. vermicularis is mebendazole or pyrantel pamoate with albendazole as an alternative treatment. Normally the treatment for E. vermicularis is 
mebendazole $100 \mathrm{mg}$ once, repeated 2 weeks later. The drug is to be given again because it does not kill the eggs, therefore it must be administrated once again to increase efficacy [11]. It is important to treat not only the patients, but also their families, as well as everyone who had contact with them in order to prevent reinfection.

\section{Conclusions}

Despite the widespread idea that acute appendicitis due to Enterobius vermicularis is very rare, it should always be considered in young female patients with repeated abdominal pain in the right lower abdomen with normal laboratory and radiologic findings. Precautions should be taken during surgery prevent spillage of pinworms in the abdominal cavity.

\section{References}

1. Panidis S, Paramythiotis D, Panagiotou D, Batsis G, Salonikidis S, Kaloutsi V, et al. Acute appendicitis secondary to Enterobius vermicularis infection in a middle-aged man: a case report. J Med Case Rep. 2011;5(1):559.

2. Fry FG. Enterobius vermicularis: 10,000 year old human infection. Science. 1969;166(3913):1620.

3. Sterba J, Vlcek M, Noll P, Vorel F. Contribution to the question of relationships between Enterobius vermicularis (L.) and inflammatory processes in the appendix. Folia Parasitol (Praha). 1985;32(3):231-5.

4. Ariyarathenam AV, Nachimuthu S, Tang TY, Courtney ED, Harris SA, Harris AM. Enterobius vermicularis infestation of the appendix and management at the time of laparoscopic appendicectomy: Case series and literature review. Int J Surg [Internet]. 2010;8(6):466-9. Available $\mathrm{f} \quad \mathrm{r} \quad \mathrm{o} \quad \mathrm{m}$ : http://dx.doi.org/10.1016/j.ijsu.2010.06.007

5. Akhigbe T, Smith F, Adeyemo A, Adeyanju T, Condon E, Waldron D. Pinworm and appendicitis in children. Internet J Surg [Internet]. 2013 [cited 2016 Dec 12];30(3):[about 4 p.]. Available from: http://ispub.com/IJS/30/3/2985

6. Dahlstrom JE, Macarthur EB. Enterobius vermicularis: a possible cause of symptoms resembling appendicitis. Aust N Z J Surg [Internet]. 1994;64(10):692-4. Available from: http://dx.doi.org/10.1016/s0031-3025(16)357300

7. Symmers WS. Pathology of oxyuriasis; with special reference to granulomas due to the presence of Oxyuris vermicularis (Enterobius vermicularis) and its ova in the tissues. AMA Arch Pathol. 1950;50(4):475-516.

8. Grimes C, Chin D, Bailey C, Gergely S, Harris A. Appendiceal faecaliths are associated with right iliac fossa pain. Ann R Coll Surg Engl. 2010;92(1):61-4.

9. Efraimidou E, Gatopoulou A, Stamos C, Lirantzopoulos N, Kouklakis G. Enterobius vermicularis infection of the appendix as a cause of acute appendicitis in a Greek adolescent: a case report. Cases J. 2008;1(1):376.

10. Da Silva DF, Da Silva RJ, Da Silva MG, Sartorelli AC, Rodrigues MAM. Parasitic infection of the appendix as a cause of acute appendicitis. Parasitol Res [Internet]. 2007;102(1):99-102. Available from: http://dx.doi.org/10.1007/s00436-0070735-0

11. Rosental PJ. Clinical pharmacology of the antihelminthic drugs. In: Katzung BG, Masters SB, Trevor AJ, editors. Basic clinical pharmacology. 12th ed. New York: McGrawHill; 2012.p. 937-9. 